\title{
A new RSC brace design to treat single long thoracic scoliosis. Comparison of the in-brace correction in two groups treated with the new and the classical models
} M Rigo* and D Gallo

\author{
Address: Institut E. Salvá. Vía Augusta 185. 08021 Barcelona, Spain \\ Email: M Rigo* - lolo_rigo@hotmail.com \\ * Corresponding author
}

\begin{abstract}
from 6th International Conference on Conservative Management of Spinal Deformities Lyon, France. 21-23 May 2009

Published: 14 December 2009

Scoliosis 2009, 4(Suppl 2):O46 doi:10.1 186/1748-716I-4-S2-O46
\end{abstract}

This abstract is available from: http://www.scoliosisjournal.com/content/4/S2/O46

(C) 2009 Rigo and Gallo; licensee BioMed Central Ltd.

\section{Purpose of the study}

The purpose of this study was to compare two different scoliosis brace designs in the treatment of a particular curve pattern.

\section{Background}

The Chêneau brace is considered one of the standards in the treatment of juvenile and adolescent idiopathic scoliosis. The RSC brace, a Chêneau derivate, uses a specific clinical and radiological classification in order to define the most effective principles of correction. (Figure 1)

\section{Methods}

In this case control study, 11 patients with long thoracic curves (imbalanced three-curve pattern or A1 from the Rigo classification) were treated with a specifically designed RSC brace called "three curves brace with open pelvis." These 11 patients were compared to a control group of 10 patients with the same age and curve magnitude, treated with a classical RSC brace for a three-curve scoliosis pattern. Patients with a combined upper thoracic structural curve were not included in any of the groups. The mean age was 10.5 years, mean Cobb angle was $29.5^{\circ}$, and mean axial rotation was $15^{\circ}$. The compared values were the in-brace correction of the Cobb angle and the axial rotation.

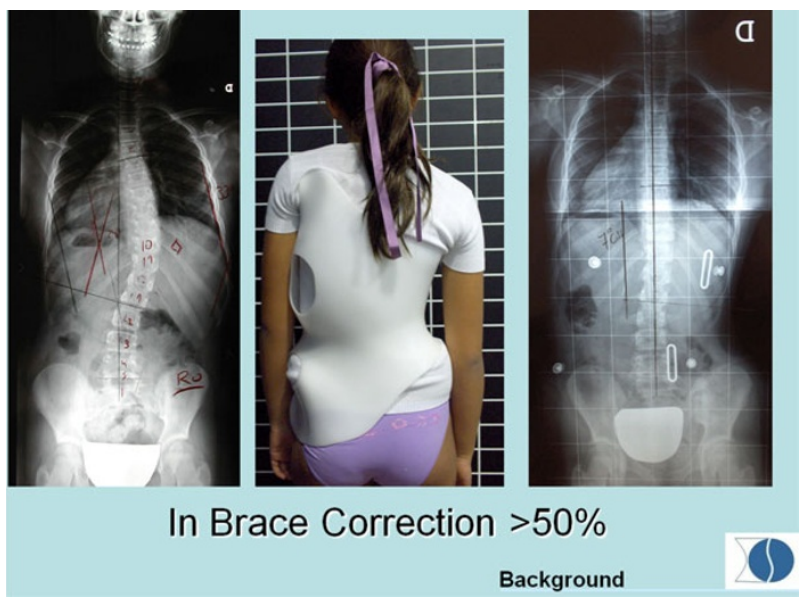

Figure I

\section{Results}

The in-brace correction of the Cobb angle was $76.7 \%$ in the study group compared to $43.3 \%$ in the control group $(\mathrm{p}<.005)$. The in-brace correction of the axial rotation was $55.9 \%$ in the study group compared to $29.9 \%$ in the control group. 


\section{Conclusion}

In-brace correction of the Cobb angle and axial rotation can be improved in patients with long thoracic curves treated with a recently described brace design ("three curves brace with open pelvis") in comparison with the classic RSC model for this curve pattern.

Publish with Bio Med Central and every scientist can read your work free of charge

"BioMed Central will be the most significant development for disseminating the results of biomedical research in our lifetime. " Sir Paul Nurse, Cancer Research UK

Your research papers will be:

- available free of charge to the entire biomedical community

- peer reviewed and published immediately upon acceptance

- cited in PubMed and archived on PubMed Central

- yours - you keep the copyright 